Revista

Ibero-Americana

de Estratégıa

\title{
UMA REVISÃO DOS FATORES DETERMINANTES PARA PROATIVIDADE AMBIENTAL: O CASO DA INDÚSTRIA CALÇADISTA
}

\section{A REVIEW OF ENVIRONMENTAL FACTORS DETERMINING TO PROACTIVITY: THE CASE OF THE FOOTWEAR INDUSTRY}

\section{UN ANÁLISIS DE LOS FACTORES AMBIENTALES QUE DETERMINAN QUE PROACTIVIDAD: EL CASO DE LA INDUSTRIA DEL CALZADO}

\section{José Carlos Lázaro}

Doutor em Planejamento Ambiental pela Technische Universität, Berlin - Alemanha

Professor da Universidade Federal do Ceará - UFC

E-mail: lazaro@ufc.br (Brasil)

\section{Monica Cavalcanti Sá de Abreu}

Doutora em Engenharia de Produção pela Universidade Federal de Santa Catarina - UFSC

Professora da Universidade Federal do Ceará - UFC

E-mail: mabreu@ufc.br (Brasil)

\section{Francisco de Assis Soares}

Mestre em Economia pela Universidade Federal do Ceará - UFC

Professor da Universidade Federal do Ceará - UFC

E-mail: soares@ufc.br (Brasil) 
Uma Revisão dos Fatores Determinantes para Proatividade Ambiental: O Caso da Indústria Calçadista

\section{UMA REVISÃO DOS FATORES DETERMINANTES PARA PROATIVIDADE AMBIENTAL: O CASO DA INDÚSTRIA CALÇADISTA}

\section{RESUMO}

Este artigo tem como objetivo analisar os fatores que levam as empresas a adotarem comportamentos ambientais proativos, estudando especificamente a indústria calçadista a partir de cinco casos do setor. Tomando como ponto de partida o modelo de González-Benito e GonzálezBenito (2006), argumenta-se, por meio deste trabalho, que a proatividade ambiental pode ser expressa por diversas práticas ambientais e estratégias. A adoção destas estratégias é influenciada por um conjunto de variáveis divididas em: fatores externos, características organizacionais e pressão das partes interessadas (stakeholders). Este trabalho avalia estas variáveis em empresas do setor calçadista. Para isso, foi realizada uma pesquisa exploratória qualitativa por meio de entrevistas e visitas as plantas produtivas em cincos empresas instaladas em dois estados brasileiros. Conclui-se que a pressão das partes interessadas é o fator determinante nas atitudes gerenciais e estratégicas, definindo a adoção de práticas ambientais nas empresas pesquisadas. Neste sentido, as estratégias ambientais variam em razão da importância percebida pelas firmas quanto às exigências das partes interessadas. Entretanto, todas as outras variáveis devem ser levadas em consideração, pelo menos como variáveis de controle nos estudos que busquem explicar e contextualizar as estratégias ambientais.

Palavras-chave: Estratégia Ambiental; Gestão Ambiental; Fatores Determinantes; Partes Interessadas.

\section{A REVIEW OF ENVIRONMENTAL FACTORS DETERMINING TO PROACTIVITY: THE CASE OF THE FOOTWEAR INDUSTRY}

\section{ABSTRACT}

This paper reviews literature in order to identify the determinant factors of companies' environmental proactivity. According to Gonzalez-Benito and Gonzalez-Benito (2006), environmental proactivity demands three practices: planning and organization, operation, and communication. Environmental strategies go on to comment upon several variables that depict internal company features, external factors, and stakeholders pressures. This work discusses these issues using data collected in 2007 from shoe companies selected for in-depth personal interviews and site visits in two different Brazilian states. The empirical results demonstrate that proactive approaches seem clear in companies influenced by stakeholders' pressure. This is the central determinant factor and it is argued that all the other variables affect either the intensity of this pressure or the company's capacity to perceive it. All the factors identified herein should be taken into account, at least as control variables, in those studies aiming at explaining and contextualizing environmental strategies.

Keywords: Environmental Strategy; Environmental Management; Determinants Factors; Stakeholders. 
José Carlos Lázaro, Monica Cavalcanti Sá de Abreu \& Francisco de Assis Soares

\section{UN ANÁLISIS DE LOS FACTORES AMBIENTALES QUE DETERMINAN QUE PROACTIVIDAD: EL CASO DE LA INDUSTRIA DEL CALZADO}

\section{RESUMEN}

Este artículo tiene como objetivo analizar los factores que las empresas llevan a adoptar conductas preventivas ambientales, específicamente el estudio de la industria del calzado a partir de cinco casos en la industria. Tomando como punto de partida el modelo de González-Benito y GonzálezBenito (2006), se argumenta, a través de este trabajo, la proactividad medioambiental se puede expresar mediante diversas prácticas y estrategias ambientales. La adopción de estas estrategias está influida por una serie de variables divididas en: factores externos, las características organizativas y la presión de grupos de interés (stakeholders). Este estudio evalúa estas variables en las empresas de la industria del calzado. Para ello, se realizó una investigación exploratoria cualitativa a través de entrevistas y visitas a plantas de producción en cinco empresas establecidas en dos Estados. Llegamos a la conclusión de que la presión de los grupos de interés es el factor determinante en las actitudes y estrategias de gestión, definiendo la adopción de prácticas ambientales en las empresas encuestadas. En este sentido, las estrategias ambientales varían debido a la importancia percibida por las empresas como a las demandas de las partes interesadas. Sin embargo, todas las otras variables se deben tomar en consideración, al menos como variables de control en los estudios que tratan de explicar y contextualizar estrategias ambientales.

Palabras-clave: Estrategia Ambiental; Gestión Ambiental; Determinantes; Partes Interesadas. 
Uma Revisão dos Fatores Determinantes para Proatividade Ambiental: O Caso da Indústria

Calçadista

\section{INTRODUÇÃO}

No Brasil, apesar de alguns pontos positivos em relação a tematização sobre a questão ambiental, observa-se um descompasso desta questão com a comunidade internacional. No início da década de 1970, quando ocorreu a alternância de paradigma ambiental na comunidade internacional, o País buscava índices de crescimento baseados em um "milagre econômico" e se encontrava sob o domínio de uma ditadura militar.

Viola (1991) analisa a evolução do ambientalismo brasileiro e identifica uma dicotomia no tratamento da questão ambiental. Por um lado, o ambientalismo stricto sensu com atuação restrita (o movimento ambiental, decorrente da ação das Organizações Não-Governamentais Ambientais ONGAs) se contrapondo, por outro, ao "ambientalismo governamental”, ou seja, o Estado agindo como agente de Comando e Controle.

Na segunda metade da década de 1980, o autor percebeu no Brasil, um "ambientalismo multissetorial". Neste são identificados, inicialmente, cinco e depois oito setores da sociedade participando e assimilando a questão ambiental. Um dos setores do ambientalismo identificados é o "ambientalismo empresarial", identificado como “[...]empresários que incorporam a dimensão ambiental na sua racionalidade microeconômica" (Viola; Boeira, 1990.p.43) ou "[...]gerentes e empresários que começam a pautar seus processos produtivos e investimentos pelo critério da sustentabilidade" (Viola; Leis, 2001, p.135).

Neste ponto, há uma intersecção histórica dessa evolução do ambientalismo à multissetorialidade, com a evolução da tematização da questão ambiental nas organizações. Podese, assim, perceber o embrião do que virá a ser a Gestão Ambiental Empresarial (Organizacional) brasileira.

Na década de 1990, alguns autores pioneiros (Donaire, 1994; 1995 e Maimon, 1994) passaram a analisar o tratamento dado para a questão ambiental dentro das organizações empresariais, a Gestão Ambiental, que deu origem a um campo dos Estudos Organizacionais (da administração) no Brasil - incluído, inclusive, na tradução do Handbook of Organizational Studies, livro de Clegg, Hardy e Nord sobre novas tendências da área (Egri; Pinfield 1996).

Ao analisar a intersecção da evolução do ambientalismo brasileiro (do tratamento dado às questões ambientais pela sociedade) com a proposição de Hoffman (1999), identifica-se uma possível influência do panorama das indústrias químicas globais. Estas empresas interferem, por meio de suas filiais nacionais, na gestação do que vem a ser chamado Gestão Ambiental 
Empresarial no Brasil. Um fator que corrobora essa interferência foi a implementação, em 1992, do programa "Atuação Responsável" (praticamente uma tradução do Responsible Care) pela Associação Brasileira da Indústria Química (Abiquim) (Barbieri, 2004).

A evolução da empresas químicas não foi completamente isolada, junto a elas, outros setores passaram a ser percebidos pelos seus impactos ao meio ambiente e, com isso, passaram a sofrer maior pressão de controle do Estado e da sociedade. Esses setores - classificados a posteriori por alguns autores como setores vermelhos em relação ao meio ambiente (Ferraz; Seroa da Mota 2002 e Masullo; Leme, 2005b) - passaram a tratar da questão ambiental estrategicamente por meio de tais programas ou princípios da indústria química. Neste contexto, empresas tornaram sua relação com o meio ambiente externo algo além de uma função de controle operacional, estabelecendo um sistema interno que passou a difundir princípios, informações e atividades relacionadas com a variável ambiental da empresa, o Sistema de Gestão Ambiental (SGA).

Gago e Antolin (2004) afirmam que as questões ambientais influenciam a rentabilidade das empresas, gerando um requisito básico para a sua incorporação nas estratégias empresariais. Então, a questão chave para a integração da gestão ambiental nas estratégias competitivas da empresa consiste em descobrir as ameaças e oportunidades e combiná-las convenientemente com suas forças e fraquezas.

A proatividade ambiental ocorre quando as empresas, voluntariamente, tomam medidas para reduzir o impacto das suas atividades, produtos e serviços no ambiente natural (Aragon-Correa, J.A, 1998; Hart, 1995; Hunt e Auster, 1990). Orsato (2006) argumenta que para algumas empresas, a melhor utilização de recursos naturais pode garantir o investimento ambiental. Para outras, a obtenção da certificação ISO 14001 ou de algum tipo de selo verde pode, eventualmente, garantir vantagens competitivas.

Neste contexto, este artigo tem como objetivo analisar, com base na revisão proposta por González-Benito e González-Benito (2006), os fatores que levam as empresas a adotarem comportamentos ambientais proativos, estudando especificamente a indústria calçadista a partir de cinco casos do setor.

Os autores, em sua revisão, propõem três grupos de fatores determinantes para a prática ambiental nas organizações: características organizacionais, fatores externos e pressão das partes interessadas.

Para atingir o objetivo pretendido, além desta introdução e da conclusão, o trabalho foi estruturado em seções. No referencial teórico discute-se os fatores determinantes para sua adoção. Em seguida, apresenta-se a metodologia para tratar o estudo de caso múltiplo em empresas do setor 
Uma Revisão dos Fatores Determinantes para Proatividade Ambiental: O Caso da Indústria

Calçadista

calçadista e os resultados encontrados. O trabalho é finalizado com uma discussão dos fatores determinantes para proatividade ambiental.

\section{FATORES DETERMINANTES QUE CONDUZEM A PROATIVIDADE AMBIENTAL NAS ORGANIZAÇÕES}

Dois dos principais pesquisadores da área de administração que tratam a gestão ambiental no Brasil, Nascimento et al (2008) e Barbieri (2004), apresentam abordagens diferentes sobre a motivação das organizações de praticarem a gestão ambiental. Enquanto Barbieri (2004), em uma perspectiva macro e abrangente, apresenta a tríade Mercado, Estado e Sociedade, Nascimento et al. (2008) analisando sobre a perspectiva estratégica, divide a análise de Gestão Socioambiental Estratégica em "ambientes” (interno, micro e macro).

A princípio, essas duas abordagens não são excludentes e dão fundamentos suficientes para estudos aprofundados na área e servem de base para este artigo. A complexidade dos fatores determinantes é apresentada tomando por base o modelo proposto por González-Benito e GonzálezBenito (2006) sendo, posteriormente, analisada pela a indústria espanhola (Gonzales-Benito, 2008; Gonzales-Benito; Gonzales-Benito, 2010). Com base neste modelo, os autores definem as características organizacionais, os fatores externos e a pressão dos stakeholders como determinantes para a proatividade ambiental, conforme figura 1.

Figura 1 - Revisão dos fatores determinantes das práticas ambientais nas organizações.

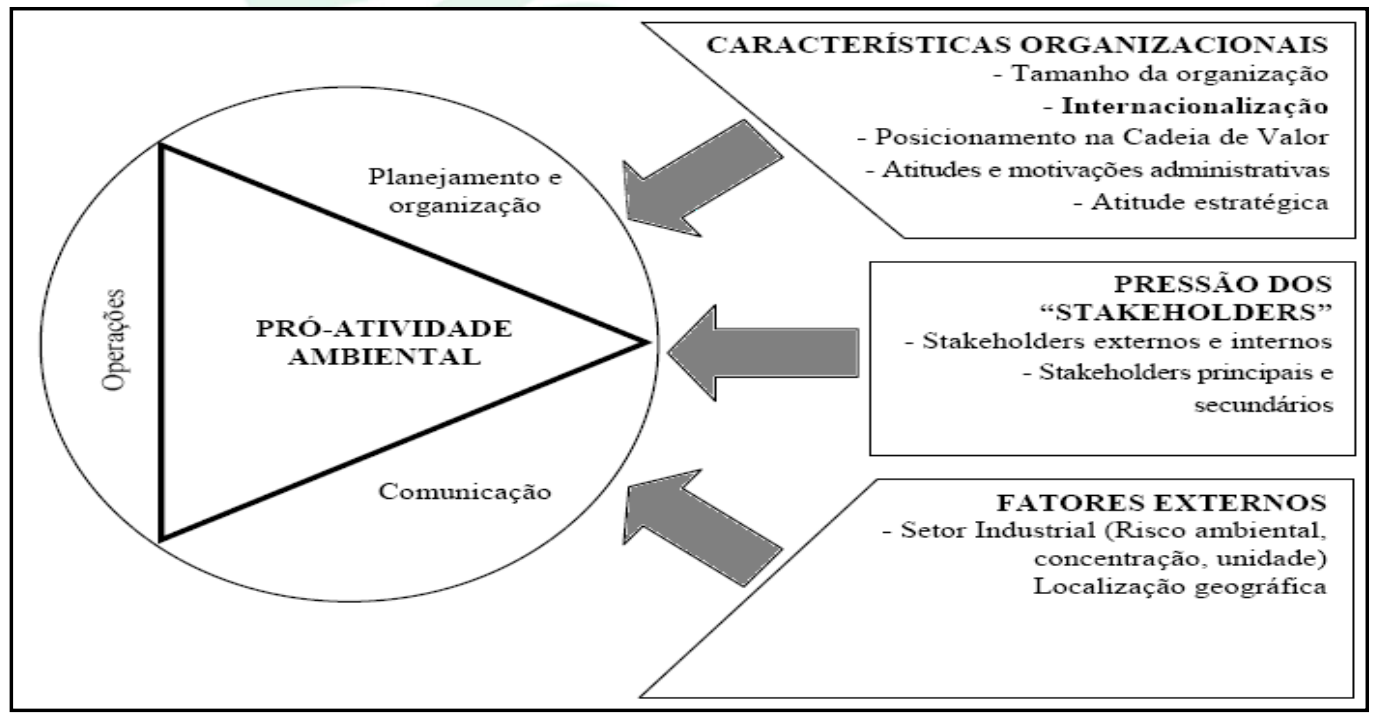

Fonte: (Gonzáles-Benito, Gonzáles-Benito, 2006).

Revista Ibero-Americana de Estratégia - RIAE, São Paulo, v. 11, n. 2, p. 197-224, mai./ago. 2012. 
José Carlos Lázaro, Monica Cavalcanti Sá de Abreu \& Francisco de Assis Soares

\subsection{CARACTERÍSTICAS ORGANIZACIONAIS}

O primeiro grupo de variáveis abrange variáveis ligadas à empresa, mas não são tipicamente variáveis "internas". $\mathrm{Na}$ realidade, elas podem ser consideradas resultantes da interação entre o microambiente e o macroambiente, conforme proposto por Nascimento Lemos e Melo (2008). Estas características organizacionais estão divididas em: o tamanho da empresa, a origem do seu capital, sua posição na cadeia de valor (frente ao consumidor final), atitudes e motivações administrativas e sua atitude estratégica.

\subsubsection{TAMANHO DA EMPRESA E ACESSO A RECURSOS}

O tamanho da empresa (medido pelo número de empregados ou pelo faturamento) tem se apresentado como uma das maiores influências na implementação de práticas ambientais. GonzálezBenito e González-Benito (2006) salientam argumentos que justificam o efeito do tamanho sobre as práticas ambientais:

a) Recursos: Essas são proporcionais ao desenvolvimento destas, ou seja, quanto maior a empresa, mais recursos são destinados à gestão ambiental. Seguindo esta perspectiva, trabalhos como os de Ferraz e Seroa da Motta (2002) e Aragon-Correa (1998) enfatizam que o tamanho pode implicar em maiores faturamento e fluxo de caixa, o que possibilita o direcionamento de recursos para questões ambientais da empresa,

b) Impacto e Controle: Seu tamanho maior expõe à pressão por parte do governo e das organizações não- governamentais. O resultado da baixa aderência da gestão ambiental em PMEs (Aragon-Correa, et al. 2008) pode assim ser analisado - o que leva os autores a explicarem as exceções. Em outras palavras, o tamanho, por ser explicitamente variável direta de impacto ambiental, ainda mais que seja comum em um estado com problemas de capacidade de controle, propicia o controle somente das grandes empresas, seja pela facilidade de identificação, seja pela facilidade de acesso. Simplificando a uma variável, independentemente do setor de atividade da organização: em uma empresa com um grande número de funcionários, questões simples, tais como saneamento e resíduos alimentares (de uma cantina) e sólidos, atingem dimensões que podem criar uma necessidade de práticas ambientais.

Revista Ibero-Americana de Estratégia - RIAE, São Paulo, v. 11, n. 2, p. 197-224, mai./ago. 2012. 
Uma Revisão dos Fatores Determinantes para Proatividade Ambiental: O Caso da Indústria Calçadista

c) Integração Institucional: Outro aspecto relacionado pelos autores espanhóis é a integração da gestão ambiental em toda organização. Por exemplo, novas tecnologias, certificações “integradas”, que, uma vez adotadas por uma parte da empresa (a matriz), passam a ser adotadas em todas as unidades.

\subsubsection{ORIGEM DO CAPITAL}

Conforme González-Benito e González-Benito (2006), Christmann e Taylor (2001) e Buysse e Verbeke (2003), ao se fazer parte de uma corporação internacional, a organização pode ser influenciada positivamente de três formas: a) ela pode ter uma transferência de conhecimento de outras unidades globais, o que facilita a adoção de novas práticas (entre elas as ambientais); b) políticas de adoção de parâmetros padrões para todas as unidades, baseadas na maior restrição; c) mesmo não sendo necessariamente uma grande empresa, pode ter a vantagem de disposição de capital para investimento na área ambiental, vindo da "matriz".

No Brasil, a variável internacionalização foi analisada por Maimon (1994), Ferraz e Seroa da Motta (2002) e Masullo e Lemme (2005a). Maimon, em seu estudo de múltiplos casos de grandes empresas atuando no Brasil, identificou uma fraqueza nesta proposição (uma negação!). Talvez haja uma questão situacional histórica nos casos analisados por Maimon (1994), ou mesmo, dentro de múltiplos casos (e não uma amostra, com análise quantitativa) possa haver um viés. Por outro lado, Ferraz e Seroa da Motta, analisando empresas do estado de São Paulo, identificaram que as empresas estrangeiras tinham mais probabilidade de fazer investimentos ambientais.

\subsubsection{POSIÇÃO NA CADEIA DE VALOR}

Esta variável parece ser mais esquecida pelos trabalhos científicos nacionais. Os autores espanhóis notam na literatura internacional a proposição teórica de uma relação entre proximidade do final da cadeia, isto é com o consumidor final, com as tendências das organizações sofrerem pressão destas partes interessadas "primárias". Buysse e Verbeke (2003) discutem esta posição na cadeia de valor como uma possível causa de resistência de algumas firmas a agirem proativamente em setores (cadeias) que não tenham sofrido uma pressão crescente dos consumidores finais.

Revista Ibero-Americana de Estratégia - RIAE, São Paulo, v. 11, n. 2, p. 197-224, mai./ago. 2012. 


\subsubsection{ATITUDE E MOTIVAÇÕES GERENCIAIS}

O envolvimento da alta gerência é essencial no desenvolvimento de uma estratégia ambiental e proatividade nas empresas. Autores que vêm estruturando a pesquisa nesta área, como Berry e Rondinelli (1998), consideram que o incentivo da gerência é um dos principais responsáveis pelo sucesso das práticas ambientais. Os gerentes têm poder de determinar um caminho, que pode ser ou não ambientalmente proativo. Os gerentes são responsáveis pelo estabelecimento de planos e diretrizes, pela avaliação de resultados e pela coordenação e controle das operações para alcançar objetivos desejados.

\subsubsection{ATITUDE ESTRATÉGICA}

Sobre esta variável, inclui-se a decisão por uma estratégia competitiva genérica, ou pela produção de serviços e bens focados no custo (commodities, onde a variável preço é a norteadora), ou a produção de serviços e bens diferenciados, onde a variável ambiental e seu mercado podem ser fatores diferenciadores. Neste caso, observam-se os casos apresentados por Almeida (2002), ou os múltiplos casos de Maimon (1994), assim como uma variedade de casos internacionais, apresentados em Rugman e Verbeke (1998) e Christmann (2000).

Nos casos citados por Maimon (1994), a autora analisa algumas companhias que adotam o processo de auditoria ambiental como uma atitude estratégica. Essas auditorias requerem um posicionamento operacional anterior coerente com a estratégia, levando ao uso de tecnologias limpas, à utilização prudente de recursos, matéria-prima e lixo industrial e à identificação de perigos e riscos potenciais.

Outra atitude estratégica muito utilizada pelas empresas é o marketing ecológico, onde um grande número de produtos é vendido pela imagem que passa, ou seja, produtos "verdes" estão ganhando espaço na preferência dos consumidores.

\subsection{FATORES EXTERNOS}

Seguindo a proposta de González-Benito e González-Benito (2006), há ainda variáveis externas a empresa, que não só interferem diretamente na pressão esperada das partes interessadas e na definição das características da organização a médio e longo prazo, como também na gestão ambiental operacional e em uma postura proativa da organização no curto prazo. 
Uma Revisão dos Fatores Determinantes para Proatividade Ambiental: O Caso da Indústria

Calçadista

\subsubsection{SETOR INDUSTRIAL}

Este parece ser o fator chave para a proatividade ambiental para vários autores. Masullo e Lemme (2005 b) extrapolam a proposta de Ferraz e Seroa da Mota (2002) de haver setores industriais extremamente poluentes (vermelho), setores poluentes (marrom) e setores com baixa carga poluente (verde). O grau de poluição do setor seria um fator que levaria as organizações a terem práticas ambientais diferentes (Tachizawa, 2005).

Tecnicamente seria uma variável básica, pois regulamentações federais e estaduais a usam como fator inicial para licenciamentos ambientais de atividade. Órgãos de controle (federal) e estaduais definem um parâmetro técnico (o potencial poluidor degradador - PPD) de cada atividade para o processo de licenciamento de cada atividade.

Com uma regulamentação mais rígida, setores industriais com maior potencial poluidor, empresas destes setores sofrem mais pressão para "gerenciar" seu impacto e, por conseguinte, exigem mais práticas ambientais (e não por menos o trabalho de Hoffman, 1999, sobre a evolução da gestão ambiental nas empresas foca o setor químico). Positivamente, a perspectiva de Porter e Linde (1995) argumentam que empresas que sofrem mais regulamentação podem buscar ser proativas e obter vantagens competitividades do atendimento de suas obrigações.

\subsubsection{LOCALIZAÇÃO GEOGRÁFICA}

González-Benito e González-Benito (2006) colocam dois aspectos fortemente ligados a localização geográfica: a legislação ambiental e a pressão social. Esses pontos também são colocados por Ferraz e Seroa da Mota e podem ser lidos como as variáveis primárias de Barbieri (2004): Estado e Sociedade. Neste artigo, propõe-se ainda introduzir nesta variável as questões geográficas ecológicas, tais como a proximidade de ecossistemas frágeis ou aglomerações populacionais, ou localização em ambientes geograficamente saturados. Estudos específicos podem aprofundar a relação entre as questões ecológicas e a legislação e pressão social.

\subsection{O PRINCIPAL DETERMINANTE: A PRESSÃO DAS PARTES INTERESSADAS}

Além de ampliar os fatores determinantes, González-Benito e González-Benito (2006) propõem que a pressão das partes interessadas pode potencializar a intensidade das variáveis apresentadas, alinhando-se com o proposto por Lyra, Gomes e Jacovine (2009). Para os autores

Revista Ibero-Americana de Estratégia - RIAE, São Paulo, v. 11, n. 2, p. 197-224, mai./ago. 2012. 
espanhóis, as partes interessadas podem ser vistas de duas maneiras, quanto ao seu grau de "contato direto" com as questões, sendo stakeholders primários e secundários, ou quanto a sua relação com a organização, stakeholders internos e externos.

Os movimentos ambientalistas, os consumidores e investidores são os maiores responsáveis pela pressão exercida sobre os órgãos que fiscalizam a poluição e que consolidam a política ambiental. É esta pressão que leva as organizações a tomarem atitudes mais conscientes no que diz respeito ao meio ambiente, ou seja, é o que vai decidir a política a ser adotada pela empresa.

As exigências partem não só de consumidores e acionistas, mas também de outras partes interessadas que podem requerer das empresas relatórios de impactos ambientais como resposta a seus investimentos ou crédito. Haddad (2002) propõe, por exemplo, que bancos federais, as agências de fomento dos Estados, assim como as agências de desenvolvimento regional, incorporem a dimensão ambiental como critérios decisivos nos seus financiamentos, para evitar danos ambientais provocados pelos projetos de investimentos subsidiados com dinheiro público ou que deixem de incentivar os projetos mais apropriados do ponto de vista do ecossistema regional e local.

Dentro dos dois conjuntos de perspectivas dos stakeholders há no vetor pressão duas questões: a intensidade e a percepção (por parte da organização) da pressão (Mitchell; Agle; Wood, 1997). Delmas e Toffel (2004) ao reconhecerem a influência que os stakeholders exercem sobre as empresas para adoção de condutas ambientalmente corretas, além disso buscaram explicar o fato de organizações que pertencem a uma mesma indústria, estando sujeitas as mesmas pressões, adotarem estratégias diferentes.

Delmas e Toffel (2004) argumentam que as forças coercitivas, leis e regulamentos, são os principais mecanismos de pressão e devido ao fato das empresas pertencerem à mesma indústria, a pressão coercitiva é a mesma para todas. Desta forma, as ações ambientais tomadas devem ser semelhantes. No entanto, Delmas e Toffel (2004) explicam que, em pesquisas realizadas com empresas operando em indústrias diferentes, foi observado que estas empresas não estavam sujeitas às mesmas pressões institucionais e, por consequência, existiam práticas ambientais distintas. Os autores constataram que níveis distintos de pressão são exercidos sobre diferentes indústrias que podem resultar em diferentes estratégias ambientais.

Levy e Rothenberg (2002) descreveram alguns fatores que explicam porque as pressões ambientais são percebidas de forma diferente pelas empresas. O primeiro deles está associado ao fato de as pressões serem filtradas e interpretadas de acordo com a cultura da organização. Em segundo lugar, os autores explicam que em uma indústria podem existir pressões conflitantes, o que acarreta priorização por parte dos gestores. Outro fator que pode acarretar a heterogeneidade é o 
fato de empresas multinacionais atuarem em vários campos, tanto em nível organizacional quanto em nível de sociedade, expondo-as a diferentes normas e práticas. D’Aunno, Succi e Alexander (2000) discorrem que as forças de mercado, como por exemplo, a proximidade com os concorrentes, também podem influenciar mudanças de estratégias que não coincidem com as práticas institucionais.

Delmas e Toffel (2004) discorrem que a estrutura organizacional, o posicionamento estratégico e o desempenho afetarão o modo de percepção das pressões e a forma de agir frente a estas, pois os indivíduos nas organizações enfocam diferentes aspectos dos ambientes interno e externo da empresa. Os autores explicam que as percepções das pressões por parte dos gestores ao nível de fábrica decorrem das ações dos stakeholders (governo; clientes, concorrentes, comunidade e grupos de interesse ambiental), mas são moderadas pelas características organizacionais da fábrica e pelo posicionamento estratégico da empresa matriz. As características da empresa e da fábrica podem afetar não somente um nível de pressão exercida sobre uma fábrica, mas também o modo como os gestores da fábrica percebem estas pressões. Isso é importante porque, mesmo que as pressões fossem exercidas no mesmo nível em duas fábricas, as duas fábricas poderiam perceber e responder de forma diferente.

Os autores discorrem que, primeiramente, as pressões são exercidas em vários níveis da empresa. Por exemplo, as pressões da comunidade são, muitas vezes, voltadas diretamente a uma determinada fábrica, enquanto as pressões dos acionistas são voltadas a um nível corporativo. Segundo, as organizações canalizam essas pressões de diferentes subunidades, cada uma das quais lida com essas pressões de acordo com suas rotinas típicas de funcionamento.

Exemplificando, os departamentos legais interpretam as pressões em termos de risco e responsabilidade legal, o departamento de assuntos externos as percebe em termos da reputação da empresa e o departamento de assuntos ambientais as interpretam em termos de dano ao ecossistema e adesão à legislação. Consequentemente a pressão é manuseada de acordo com o arcabouço cultural da unidade que a recebe. Os gestores da fábrica podem perceber essas pressões externas de forma mais intensiva nas empresas em que eles têm canais mais abertos de comunicação com os stakeholders.

Revista Ibero-Americana de Estratégia - RIAE, São Paulo, v. 11, n. 2, p. 197-224, mai./ago. 2012. 
José Carlos Lázaro, Monica Cavalcanti Sá de Abreu \& Francisco de Assis Soares

\section{METODOLOGIA}

O procedimento metodológico para o atendimento aos objetivos propostos nesta pesquisa permite classificar este trabalho como exploratório e descritivo. A pesquisa exploratória (Piovesan, Temporini, 1995) permitirá identificar os fatores determinantes da proatividade ambiental de múltiplos casos no setor calçadista (seguindo as diretrizes de Yin, 2010, 76-84). A pesquisa é descritiva, com a utilização da técnica padronizada de coleta de dados, e nela foram utilizados dois instrumentos, um roteiro de entrevista e um questionário fechado com escala likert sobre os temas perguntados, com o intuito de contornar possíveis não respostas a certos temas do roteiro. Quatro as entrevistas foram conduzidas em visitas as unidades de produção e gestão das empresas, foi possível efetuar observação local dos procedimentos. Com a observação local e os dados secundários fornecidos foi feita a triangulação de dados para análise final (Yin, 2010; Denzin; Lincoln, 2006 Flick, 2009;). Quanto aos procedimentos, a pesquisa classifica-se como pesquisa de campo, por ter obtido os dados diretamente do local de ocorrência.

Por fim, quanto à forma de abordagem, classifica-se como qualitativa. As informações obtidas não podem ser quantificáveis, os dados são analisados indutivamente e a interpretação dos fenômenos e a atribuição de significados são premissas no processo de pesquisa qualitativa.

\subsection{ELABORAÇÃO DO INSTRUMENTO DE COLETA DE DADOS}

O instrumento de coleta de dados foi dividido em duas partes. Um questionário estruturado, que continha questões fechadas, e um roteiro de entrevista com questões abertas, em que o entrevistado poderia expressar livremente sua opinião.

Estes questionários levantavam questões sobre as práticas ambientais, as características organizacionais, os fatores externos e a pressão dos stakeholders. As práticas ambientais foram questionadas de forma estruturada envolvendo aspectos operacionais, organizacionais e de comunicação. Foram também levantadas por meio de questões estruturadas de autoanálise do desempenho ambiental, as atitudes e motivações gerenciais e atitudes ambientais estratégicas, tomando por base pesquisas desenvolvidas por Abreu et al (2008).

As empresas foram também questionadas sobre as características organizacionais (posicionamento na cadeia de valor, internacionalização e tamanho da organização) e a influência dos stakeholders na adoção de práticas ambientais. Em particular, foram questionadas a atuação do órgão de fiscalização ambiental e quais eram as exigências "ambientais" dos clientes nacionais e internacionais.

Revista Ibero-Americana de Estratégia - RIAE, São Paulo, v. 11, n. 2, p. 197-224, mai./ago. 2012. 
Uma Revisão dos Fatores Determinantes para Proatividade Ambiental: O Caso da Indústria

Calçadista

\subsection{DEFINIÇÃO DAS EMPRESAS PARA A COLETA DE DADOS NO SETOR CALÇADISTA}

A pesquisa foi desenvolvida em indústrias calçadista em 2007. O critério de semelhança tecnológica foi utilizado na seleção das empresas para as entrevistas. A escolha dos casos a serem estudados foi, portanto, intencional e não-probabilística. Depois de identificado o universo das indústrias, buscou-se o contato com as empresas (telefone e correio eletrônico).

A pesquisa identificou cinco empresas da indústria calçadista que apresentam explicitamente fatores diferenciados. Duas destas empresas estão no pólo calçadista do Rio Grande do Sul (denominadas na pesquisa de R1 e R2) e as outras três destas empresas estão localizadas no Estado do Ceará (denominadas de C1, C2 e C3). Uma empresa faz parte do pólo calçadista ("histórico") da Região do Cariri/CE (C1), uma migrou do Rio Grande do Sul para o Ceará (C2) e outra é uma unidade que migrou de São Paulo (C3), mas mantém os acionistas no sul do Brasil.

A quinta empresa $(\mathrm{C} 3)$ restringiu o acesso, o que de certa forma era esperado, devido às características administrativas e estratégicas que se identificam por dados secundários. A empresa caracteriza-se como uma sociedade "aparentemente" aberta, entretanto, percebe-se a ausência de governança corporativa explícita na carência de dados a investidores nas publicações obrigatória da Bovespa.

\subsection{ANÁLISE DOS DADOS COLETADOS NAS EMPRESAS DO SETOR CALÇADISTA}

Por fim, realizou-se o tratamento dos dados coletados nas entrevistas, com vistas à compreensão dos fatores determinantes da proatividade ambiental, segundo o modelo de GonzálezBenito e González-Benito (2006). Cada entrevista demorava, em média, 2 horas e foram realizadas com gerentes industriais, gestores da área de meio ambiente ou de planejamento estratégico. Os questionários eram preenchidos à medida que a entrevista era conduzida. As empresas receberam o questionário (com antecedência via email) a fim de identificar os gestores responsáveis para fornecer informações precisas. De acordo com os procedimentos metodológicos adotados e os casos investigados, os resultados estão apresentados em: práticas ambientais, características organizacionais, fatores externos e pressões dos stakeholders.

Revista Ibero-Americana de Estratégia - RIAE, São Paulo, v. 11, n. 2, p. 197-224, mai./ago. 2012. 


\section{RESULTADOS}

\subsection{PRÁTICAS AMBIENTAIS ADOTADAS}

A pesquisa revela que as empresas R1, R2 e C2 apresentam boas práticas ambientais. De uma forma geral, as empresas pesquisadas possuem na sua estrutura organizacional um responsável para tratar das questões ambientais e existe um compromisso da organização com a responsabilidade ambiental. A política ambiental estabelece compromissos para atender a legislação ambiental, a melhoria contínua dos processos e a prevenção da poluição. Essas empresas possuem instrumentos para acompanhar a legislação ambiental. Os investimentos ambientais são definidos com base nos objetivos e nas metas ambientais que são acompanhados de forma sistemática por meio de indicadores estabelecidos com base nos padrões legais.

$\mathrm{Na}$ área de desenvolvimento de produtos e processos têm se tentado adotar tecnologias que minimizem os impactos ambientais dos seus processos produtivos, para isso, fazem o levantamento e a avaliação dos aspectos e impactos ambientais de suas atividades, produtos e serviços. As empresas realizam auditorias ambientais. Os controles operacionais estão implantados ou em processo de revisão. Os ganhos financeiros estão ligados à redução de perdas do processo.

As empresas possuem, ou estão implantando, programas de educação ambiental. Na área de comunicação, as empresas desenvolvem uma sistemática para registro e atendimento das reclamações ambientais das partes interessadas. As empresas pesquisadas têm sistemas de gestão ambiental certificados pela ISO 14001 ou estão em processo de certificação.

Por outro lado, as empresas C1 e C3 apresentam fracas práticas ambientais e se comportam com omissão. Não possuem uma política ambiental escrita e a importância do meio ambiente para a empresa está limitada ao atendimento aos condicionantes das licenças ambientais. Os investimentos em meio ambiente são definidos para atender a fiscalização ambiental. Nestas empresas não existem programas de educação ambiental ou de coleta seletiva.

A implantação de um Sistema de Gestão Ambiental - SGA, conforme a NBR ISO 14001, não faz parte dos planos das empresas C1 e C3. Os controles operacionais estão voltados prioritariamente aos insumos de processo: matéria-prima e energia elétrica. A auditoria ambiental não é realizada e as empresas também não adotam indicadores ambientais. As empresas não possuem um canal de comunicação com as partes interessadas para tratar das reclamações ambientais e não produzem relatórios ambientais. Enfim, enxergam as questões ambientais como custo sem a promoção de vantagem competitiva.

Revista Ibero-Americana de Estratégia - RIAE, São Paulo, v. 11, n. 2, p. 197-224, mai./ago. 2012. 
Uma Revisão dos Fatores Determinantes para Proatividade Ambiental: O Caso da Indústria Calçadista

A seguir é apresentada a análise individual de cada empresa pesquisada, levando a uma configuração das características organizacionais determinantes da proatividade ambiental (tamanho da empresa e acesso a recursos; internacionalização do capital acionista; posição da empresa na cadeia de valor; atitude e motivação gerencial e atitude estratégica).

\subsection{CARACTERÍSTICAS ORGANIZACIONAIS}

\subsubsection{EMPRESA R1}

É uma empresa com uma gestão ambiental avançada, com práticas explícitas e com um SGA próprio e plano de implementação da ISO 14001. Analisando os fatores determinantes da adoção de práticas ambientais observa-se:

- Tamanho da empresa e acesso a recursos: A empresa é de grande porte, sendo a unidade de calçados (infantis) o resultado de um processo de horizontalização de uma empresa com foco em produção de vestimentas infantis. O acesso a recursos não parece ser problema.

- Origem do capital acionista: O capital da empresa é nacional.

- Posição na Cadeia de Valor: É uma empresa que chega com sua marca no final da cadeia de valor, tendo, inclusive, lojas com sua marca.

- Atitude de Motivação Gerencial: A entrevista identificou claramente uma motivação gerencial positiva. A questão ambiental representa um ganho de imagem, passando para os clientes um sentimento positivo em relação à empresa e agregando valor ao produto, que interliga o meio ambiente, a produtividade dos recursos, a inovação e a competitividade.

- Atitude Estratégica: as práticas ambientais parecem estar ligadas a atitude estratégica da empresa. Ao desenvolver uma marca própria de "valor diferenciado" e com foco no público infantil, buscando, inclusive, a difusão da marca no exterior, faz com que a empresa siga a tendência de maior conscientização ambiental dos mercados mais exigentes.

Revista Ibero-Americana de Estratégia - RIAE, São Paulo, v. 11, n. 2, p. 197-224, mai./ago. 2012. 


\subsubsection{EMPRESA R2}

É uma fabricante de calçados femininos para exportação (90\%), com boas práticas ambientais e com a visão de uma gestão ambiental integrada a qualidade. Com relação aos fatores determinantes, observa-se:

- Tamanho da Empresa e Acesso aos Recursos: é uma empresa de médio porte, sendo a disponibilidade de recursos para gestão ambiental nem escasso e nem ilimitado.

- Origem do Capital Acionista: é uma empresa de capital nacional.

- Posição na Cadeia de Valor: é uma empresa completamente verticalizada, chegando até o consumidor final.

- Atitude e Motivação Gerencial: Existe uma motivação gerencial para a gestão ambiental. A gerência destaca que todas as unidades da empresa são implementadas (independentemente do local e das exigências legais) com os parâmetros instituídos pela diretoria.

- Atitude Estratégica: A estratégia da empresa é focada no mercado internacional, em sapatos femininos de qualidade diferenciada. Mesmo assim, não usa a gestão ambiental como diferencial (inclusive não buscando certificações)

\subsubsection{EMPRESA C1}

A empresa fabrica sandálias em PVC. Apresenta limitadas práticas ambientais e opera no limite da legislação (para baixo). Foi autuada recentemente por deposição ilegal de resíduos sólidos. $\mathrm{Na}$ entrevista, o gestor mostrou inconformidade com a autuação (alegando desinformação sobre a regulamentação básica de deposição de lixos industriais). Observa-se que:

- Tamanho da Empresa e Acesso aos Recursos: Uma empresa de porte pequeno, o que restringe o capital para a aplicação em práticas ambientais.

- Origem do capital acionista: Capital totalmente local e familiar.

- Posição na cadeia de valor: É uma processadora de produto final, isto é fornece para as empresas varejistas que vendem o produto ao consumidor final.

- Atitude de motivação gerencial: Durante a entrevista, nota-se uma falta de motivação gerencial para as práticas ambientais ou mesmo de gestão da qualidade (onde boa parte do questionário estruturado, respondido por um dos diretores ficou em branco). 
Uma Revisão dos Fatores Determinantes para Proatividade Ambiental: O Caso da Indústria Calçadista

- Atitude estratégica: Não possui uma marca consolidada no mercado, opta por fornecer produtos commodities de baixo valor (cópias de produtos de marca - sem falsificação).

\subsubsection{EMPRESA C2}

Esta empresa participa no grupo de trabalho da Global Report Initiative que visa ao estabelecimento de parâmetros de sustentabilidade para o setor. Embora não tenha apresentado um SGA claramente estruturado com base na ISO14001, apresenta uma política de responsabilidade ambiental, com indicadores de desempenho ambiental.

- Tamanho da empresa e acesso aos recursos: É uma empresa de grande porte, o que justifica o acesso a recursos para práticas ambientais - talvez seja um caso típico deste determinante.

- Origem do capital acionista: Embora o capital aberto da empresa ainda seja controlado por acionistas nacionais, a sua posição na Bovespa no "Novo Mercado" apresenta-se com alto índice de governança corporativa. A empresa mostra-se em fase crescente de internacionalização.

- Posição na cadeia de valor: É uma empresa verticalizada a partir da aquisição da matéria-prima. Atua direto no consumidor, tendo como preocupação central a divulgação e a logística dos seus produtos.

- Atitude e motivação gerencial: Tanto na entrevista quanto na leitura de seu relatório anual fica explícita a motivação gerencial por práticas ambientais, dentro de uma perspectiva de responsabilidade social como elemento de governança corporativa.

- Atitude estratégica: A atitude estratégica ampla, de fixação de marcas diferenciadas, de desenvolvimento de mercados externos inclui a gestão ambiental (e social) dentro dos níveis internacionais.

Revista Ibero-Americana de Estratégia - RIAE, São Paulo, v. 11, n. 2, p. 197-224, mai./ago. 2012. 


\subsubsection{EMPRESA C3}

No setor tem-se a empresa como uma cumpridora de exigências mínimas, sendo que na migração de suas unidades para o nordeste foi aproveitado explicitamente o seu peso político para protelar qualquer prática ambiental mais "custosa".

- Tamanho da empresa e acesso aos recursos: C3 é uma das maiores empresas do setor no Brasil, assim o acesso a recursos para práticas ambientais deveria ser facilitado, assim como a exposição à sociedade e mídia. Estrategicamente, fora de seu município de instalação, a empresa busca a menor exposição possível.

- Origem do capital acionista : A empresa tem capital aberto, com baixa governança e com controle familiar.

- Posição na cadeia de valor: A empresa fornece produtos diretamente ao consumidor final.

- Atitude de motivação gerencial: Percebe-se claramente (até pela dificuldade de acesso) que há uma posição gerencial resistente a gestão ambiental, além da legal (ou de um limite que não gere exposição).

- Atitude estratégica: A empresa tem uma estratégia focada na redução de custos, concorrendo com empresas chinesas como fornecedor de produtos de segunda linha para grandes marcas mundiais.

\subsection{FATORES EXTERNOS}

\subsubsection{SETOR INDUSTRIAL}

De acordo com González-Benito e González-Benito (2006), Masullo e Leme (2005a, 2005b) e Ferraz e Seroa Motta (2002), é fundamental caracterizar o "fator determinante" setor industrial. As cinco empresas fazem parte do setor calçadista, no entanto, somente a unidade da R2 processa (parcialmente) o couro.

Por outro lado, as outras empresas analisadas podem ser consideradas da indústria calçadista sintética (ou seja, com alto uso de PVC e baixo nível de resíduos). Têm-se duas opções de análise: ou se considera este um setor "marrom" (setores poluentes) ou um setor verde (com baixa carga poluente). Neste artigo, em razão da predominância de empresas da indústria calçadista sintética, optou-se por identificar as empresas entrevistadas como "verdes".

Revista Ibero-Americana de Estratégia - RIAE, São Paulo, v. 11, n. 2, p. 197-224, mai./ago. 2012. 
Uma Revisão dos Fatores Determinantes para Proatividade Ambiental: O Caso da Indústria

Calçadista

\subsubsection{LOCALIZAÇÃO GEOGRÁFICA}

- A empresa R1 está instalada no Rio Grande do Sul, um dos estados mais rigorosos no comando e controle ambiental; no vale dos Sinos, onde há um controle intenso.

- A empresa R2 tem a maioria da suas unidades no Rio Grande do Sul, onde o comando e controle ambiental são exigentes, no entanto, as duas unidades no nordeste brasileiro seguem os mesmos padrões de práticas ambientais.

- A empresa C1 se localiza na Região do Cariri Cearense, onde o peso político de empresas com problemas ambientais aliados a falta de estrutura do órgão de controle estadual não estimulam as empresas a, pelo menos, cumprirem as leis ambientais básicas.

- Na_empresa C2 ocorreu a migração da matriz do Rio Grande do Sul para um estado do nordeste (CE), onde o controle ambiental é menor. Entretanto, a influência de grandes investidores é politicamente maior (empresas como geradoras de emprego e renda), o que implica na manutenção de um padrão internacional. Durante a entrevista, os gestores afirmaram que "não consideram ética a exploração da situação de carência social e econômica para diminuir ou excluir práticas ambientais.”

- A empresa C3 migrou de São Paulo para um pequeno município do Ceará (longe do pólo do Cariri). A empresa fez essa opção em razão dos incentivos fiscais, decorrentes da política de renúncia fiscal para atrair investimentos na região.

\subsection{PRESSÃO DOS STAKEHOLDERS}

A pesquisa revela que a fiscalização e a regulação ambiental são fatores determinantes para as empresas calçadistas adotarem práticas ambientais. As empresas afirmaram que a fiscalização é mais eficiente no Rio Grande do Sul, quando comparadas com a existente no Estado do Ceará. Contudo, a pressão de outros stakeholders, além dos órgãos de fiscalização ambiental, está associada ao seu poder e legitimidade, conforme ditam Mitchell, Agle e Wood (1997).

Todas as empresas calçadistas revelaram que os stakeholders mais importantes nas decisões estratégicas são os acionistas e os clientes do mercado interno e externo. Paralelamente, estas empresas afirmaram dedicar um foco mínimo de atenção às comunidades no entorno da fábrica (por que não existem) e as ONGs (que não colocam a indústria calçadista como alvo de suas ações). 
Os clientes das empresas calçadistas estão, principalmente, preocupados com o preço, o prazo de entrega e a qualidade dos produtos. Os clientes não possuem explicitamente exigências em termos de certificações ambientais ou divulgação de relatórios de sustentabilidade. Entretanto, as empresas R1, R2 e C2 estão preocupadas em transmitir uma imagem de empresas socialmente responsáveis.

\section{ANÁLISE E DISCUSSÃO DOS RESULTADOS}

A figura 2 apresenta as empresas pesquisadas, as práticas ambientais adotadas, as características organizacionais, os fatores externos e a pressão resultante dos stakeholders. Nesse ponto, se deve voltar a questão apresentada por González-Benito e González-Benito (2006) que consiste na inter-relação entre os fatores. Desta forma, a abordagem analítica a ser adotada é de exclusão. Inicialmente, exclui-se a generalização que um setor tem comportamento homogêneo em relação às práticas ambientais. O estudo de Silva et al. (2008) já chegava a esta conclusão sobre o setor de saneamento.

Partindo para a análise do tamanho, isto é, o porte da empresa, observa-se que R1 e C2 são empresas de grande porte e confirmam esta variável como determinante para proatividade ambiental. R2 é uma empresa de médio porte e não possui uma alta disponibilidade de capital, contudo, adota boas práticas ambientais. Por outro lado, C3 pelo seu grande porte tem alta disponibilidade de capital, no entanto, não dispõe esse capital para investimentos em práticas ambientais.

Figura 2- Análise de práticas ambientais, características organizacionais, fatores externos e pressão dos stakeholders.

\begin{tabular}{|c|c|c|c|c|c|c|c|c|}
\hline \multirow{2}{*}{ Empresa } & \multirow{2}{*}{$\begin{array}{c}\text { Práticas } \\
\text { ambientais }\end{array}$} & \multicolumn{5}{|c|}{ CARACTERÍSTICAS ORGANIZACIONAIS } & \multirow{2}{*}{$\begin{array}{c}\text { Fatores } \\
\text { externos }\end{array}$} & \multirow{2}{*}{$\begin{array}{c}\text { Pressão } \\
\text { dos } \\
\text { stakeholders }\end{array}$} \\
\hline & & Tamanho & $\begin{array}{c}\text { Origem do } \\
\text { capital }\end{array}$ & $\begin{array}{c}\text { Cadeia } \\
\text { de valor }\end{array}$ & $\begin{array}{l}\text { Atitudes } \\
\text { gerenciais }\end{array}$ & $\begin{array}{l}\text { Atitudes } \\
\text { estratégicas }\end{array}$ & & \\
\hline R1 & Boas & G & $\mathrm{Nac}$ & Final & Compr & Dif/Int & Geo+ & Forte \\
\hline R2 & Boas & M & $\mathrm{Nac}$ & Final & Compr & Dif/Int & Geo+ & Forte \\
\hline
\end{tabular}

Revista Ibero-Americana de Estratégia - RIAE, São Paulo, v. 11, n. 2, p. 197-224, mai./ago. 2012. 
Uma Revisão dos Fatores Determinantes para Proatividade Ambiental: O Caso da Indústria

Calçadista

\begin{tabular}{|c|c|c|c|c|c|c|c|c|}
\hline $\mathbf{C 1}$ & Fracas & $\mathrm{P}$ & Fam & Varejo & Omisso & Custo & Geo- & Fraca \\
\hline $\mathbf{C 2}$ & Boas & $\mathrm{G}$ & $\mathrm{Ab} \mathrm{Nac+}$ & Final & Compr & Dif/Int & Geo- & Forte \\
\hline $\mathbf{C 3}$ & Fracas & $\mathrm{G}$ & $\mathrm{Ab} \mathrm{Nac+}$ & Final & Resist & Custo & Geo- & Fraca \\
\hline
\end{tabular}

\section{Legenda}

Tamanho: grande $(\mathrm{G})$, médio $(\mathrm{M})$, pequeno $(\mathrm{P})$

Origem do capital: capital aberto com predominância de investidores nacionais (Ab Nac+), familiar (Fam), capital fechado nacional (Nac)

Cadeia de valor: consumidor final (Final), varejo (Varejo)

Atitudes gerenciais: comprometido (Compr), resistente (Resit), Omisso (Omiss) frente às questões ambientais

Atitudes estratégicas: diferenciação com foco no mercado internacional (Dif/Int), custo (Cus)

Fatores externos: localização geográfica influencia a adoção de práticas ambientais (Geo+), localização geográfica não influencia (Geo-)

Quadro destacados indicam a incoerência com as proposições teóricas usuais

Fonte: Gerado a partir das pesquisas de campo.

A segunda característica refere-se a origem do capital. As empresas R1 e R2 têm controladores nacionais e investem em boas práticas. Corroborando com a literatura, C2 apresenta a posição na Bovespa no "Novo Mercado" com alto índice de governança corporativa, com internacionalização crescente e boas práticas ambientais. A empresa C3 tem capital aberto, com predominância nacional e apresenta característica de baixa governança e fracas práticas ambientais. A empresa $\mathrm{C} 1$ tem uma administração familiar, com capital nacional e também adota fracas práticas ambientais.

A posição na cadeia de valor parece uma novidade coerente trazida por González-Benito e González-Benito (2006). No entanto, C3 com suas práticas limitadas e estando no final da cadeia nega este fator.

Parece que as práticas ambientais estão fortemente relacionadas com as atitudes gerenciais e estratégicas. As duas últimas características organizacionais parecem ser as mais coerentes com os cinco casos escolhidos. Dados secundários, as visitas e as entrevistas identificaram as posturas gerenciais e estratégicas das empresas extremamente coerentes com suas práticas ambientais, tanto positivamente em R1, R2 e C2, quanto negativamente em C1 e C3. Entende-se aqui que as práticas ambientais em R2 são definidas pela atitude gerencial e ética dos proprietários da empresa.

Revista Ibero-Americana de Estratégia - RIAE, São Paulo, v. 11, n. 2, p. 197-224, mai./ago. 2012. 
Essa postura acaba sendo corroborada (em parte) pela segunda variável externa (além do setor), a localização. Analisando empresas localizadas em dois estados com regulamentação e, sobretudo, com controles ambientais diferentes, esperava-se que houvesse uma clara definição da dependência da localização. No entanto, C2 com suas boas práticas ambientais nega este fator como determinante, e R2, com algumas unidades, no nordeste também.

Voltando então aos fatores ligados a percepção das pressões ambientais e a atitude gerencial e estratégica em resposta a estas pressões, observa-se que R1, R2 e C2 são fortemente pressionados por outros stakeholders, que envolvem os acionistas, os clientes do mercado interno e externo, além dos órgãos de fiscalização ambiental. Estas empresas atuam com uma estratégia de diferenciação com foco no mercado internacional. Para as empresas $\mathrm{C} 1$ e $\mathrm{C} 3$, a baixa exigência ambiental dos clientes conduz somente a adequação à legislação, tornando qualquer investimento acima do padrão legal exigido um custo que deve ser evitado.

Estas empresas (C1 e C3) competem com uma estratégia baseada em custos. Dessa forma, ao entrarem no mercado com produtos com preços baixos deixam de lado as questões ambientais e realizam apenas os controles necessários para o cumprimento da legislação (se a fiscalização atuar).

Sabe-se que a proatividade ambiental requer a adequação de processos de produção. Tal modificação demanda investimentos por parte da empresa. Em um cenário em que as empresas estão perdendo competitividade, fruto da abertura econômica e da pressão das importações de produtos chineses, as empresas que não participam do mercado internacional com produtos diferenciados identificam a proatividade ambiental como uma vantagem competitiva.

\section{CONSIDERAÇÕES FINAIS}

Os resultados da pesquisa no setor calçadista confirmam a diversidade de fatores determinantes da proatividade ambiental, no modelo proposto por González-Benito e GonzálezBenito (2006). Levando-se em consideração a diversidade, esta pesquisa apresentou empresas que adotam diferentes práticas ambientais, mesmo que simplificadamente apresentada no quadro 1 como "Boas" ou "Fracas" e uma diversidade de características organizacionais, mesmo quando isolado o setor industrial. Como questão interessante, verificou-se que todas as empresas entrevistadas têm seu capital nacional, com origem familiar (mesmo as empresas de capital aberto seguem com o domínio acionário de uma família de empreendores. Como resultado tem-se empresas proativas não internacionalizadas de capital, mas com internacionalização de mercado.

Revista Ibero-Americana de Estratégia - RIAE, São Paulo, v. 11, n. 2, p. 197-224, mai./ago. 2012. 
Uma Revisão dos Fatores Determinantes para Proatividade Ambiental: O Caso da Indústria

Calçadista

No quadro resumo 1, ficou exposto que as práticas ambientais são resultados da intensidade da pressão exercida pelas partes interessadas, pois onde há uma pressão forte tem-se boas práticas ambientais, ou seja uma proatividade "pressionada". No entanto, esta pressão não está vinculada a apenas uma característica organizacional encontrada na revisão da literatura. Ao perceber que mesmo em uma indústria isolada não há isonomia de características organizacionais e que alguns fatores isolados não explicam nem a pressão e nem as boas práticas, o resultado deste estudo acaba se alinhando com os resultados do estudo quantitativo dos autores do modelo (Gonzales-Benito; Gonzales-Benito, 2010) onde nem todos os fatores são relevantes isoladamente. A empresa C3 acaba sendo a geradora de maior conflito com as propostas teóricas da proatividade, sendo que uma empresa grande, de capital aberto, focada no consumidor (final da cadeia de valor), tenderia a se esperar uma boa proatividade, no entanto os fatores internos se sobrepõem, pois se identifica nessa uma estratégia de foco nos custos e resistência a práticas ambientais, parecendo só alinhado a proposta teórica da localização geográfica. Por outro lado, C2 nega exatamente a proposta teórica do fator externo geográfico, tendo uma postura proativa independente de sua localização em um local onde pressões são menores. Esta negação do proposto tanto por Gonzalez-Benito e GonzalesBenito (2006) quanto pelo estudo de Ferraz e Seroa da Mota (2002) expõe uma das principais reflexões sobre a gama de fatores externos propostos: eles independentemente não definem a proatividade.

Não há como negar que há diferentes pressões sendo exercidas em empresas do mesmo setor, e o resultado deste projeto parece expor que os fatores internos, enfatizados por Lyra, Gomes e Jacovine (2009) e Delmas e Toffel (2004), são fundamentais para a gestão e priorização estratégica das questões ambientais.

Os gerentes estão constantemente sendo exigidos por justificativas mais sólidas em termos de estratégias ambientais a serem desenvolvidas nas empresas. Fundamentalmente, as empresas devem se perguntar: Quem está valorizando meus investimentos ambientais? A partir desta avaliação da pressão dos stakeholders, a estratégia ambiental a ser adotada consiste em fazer o melhor se diferenciando da concorrência.

Os autores reconhecem as limitações de um estudo qualitativo. Contudo, essa pesquisa cumpre sua função exploratória e contribui para a elaboração de hipóteses e definição de variáveis que podem ser testadas em pesquisas quantitativas (Benito-Gonzales; Benito-Gonzales, 2010; Masullo E Lemme, 2005a) que envolvem a complexidade do tema proatividade ambiental.

Revista Ibero-Americana de Estratégia - RIAE, São Paulo, v. 11, n. 2, p. 197-224, mai./ago. 2012. 


\section{REFERÊNCIAS}

Abreu, M. C. S., Silva Filho, J. C. L.,Oliveira, B. C., Holanda Junior, F.L.(jan.abr. 2008) Perfis estratégicos de conduta social e ambiental: estudos na indústria têxtil nordestina. Gestão \& Produção, 15(1), 159-72. Doi: 10.1590/S0104-530X2008000100014

Almeida, F.(2002) Negócio da Sustentabilidade. (2002) Rio de Janeiro: Nova Fronteira.

Aragon-Correa, J. A. Hurtado-Torres, H. , Sharma, S., Garcia-Morales, V. J..(2008) Environmental strategy and performance in small firms: A resource-based perspective. Journal of Environmental Management, 86(1), 88-103.

Aragon-Correa, J. A.(1998) Strategic proactivity and firm approach to the natural environment. Academy of Management Journal, 41(5), 556-567. Doi: 10.2307/256942

Barbieri, J. C.(2004) Gestão ambiental empresarial: conceitos modelos e instrumentos. São Paulo: Saraiva. 328 p.

Berry, M. A., Rondinelly, D. A.(1998) Proactive corporate environmental management: a new industrial revolution. Academy of Management Executive, 12(2).

Buysse, K., Verbeke, A. (2003) Proactive environmental strategies: a stakeholder management perspective. Strategic Management Journal, 24(5), 453-470. Doi: 10.1002/smj.299

Castro Neto, F. C., Oliveira, J. C, C., Pitombeira, L. G., Silva Filho, J. C. L., Abreu, M. C. S.(2011) Fatores determinantes de proatividade ambiental em empresas cearenses: estudo de casos múltiplos. RGSA: Revista de Gestão Social e Ambiental, v. 5, 4.

Christmann, P.(ago. 2000) Effects of "best practices" of environmental management in cost advantage: The role of complementary assets. Academy of Management Journal, 43(4), 663-680. Doi: $10.2307 / 1556360$

Christmann, P., Taylor, G.(2001) Globalization and the environment: determinants of firm selfregulation in China. Journal of International Business Studies, 32(3), 439-458. Doi: 10.1057/palgrave.jibs.8490976

D`Aunno, T., Ucci, M., Alexander, J. A.t al. (December, 2000) The role of institutional and market forces in divergent organizational change. Administrative Science Quartely. 45(4), 679-703. Doi: $10.2307 / 2667016$

Delmas, M., Toffel, M. W. (2004) Stakeholders and environmental management practices: an institutional framework. Business Strategy and the Environment, 13: 209-222. Doi: $10.1002 / \mathrm{bse} .409$ 
Uma Revisão dos Fatores Determinantes para Proatividade Ambiental: O Caso da Indústria Calçadista

Denzin, N.K.; Lincoln, Y. S. (2006) O planejamento da pesquisa qualitativa: teorias e abordagens. Porto Alegre: Artmed Bookman.

Donaire, D. (1995) Gestão ambiental na empresa. São Paulo: Atlas.

Donaire, D. (março/abril 1994) Considerações sobre a influência da variável ambiental na empresa. Revista de Administração, São Paulo, 34(12), 68-77.

Egri, C. P. \& Pinfield, L. T.(1996) Organizations and the biosphere: ecologies and environmental. In: Clegg, S., Hardy,C.. \& Nord, W.R. Handbook of Organization Studies. London, Sage: 459483.

Ferraz, C., Seroa Da Mota, R.(2002) Regulação, mercado ou pressão social? os determinantes do investimento ambiental na indústria. IPEA: Texto para Discussão No 863. IPEA: Rio de Janeiro

Flick, U. (2009) Introdução à pesquisa qualitativa. Porto Alegre: Bookman Artmed.

Gago, R. F., Antolin, M. N.(2004) Environmental management and strategic positionig of spanish manufacturing industries. Business Strategy and the Environment. v.13, 33-42. Doi: $10.1002 /$ bse. 391

González-Benito, J., González-Benito, Ó (2006). A review of determinant factors of environmental proactivity. Business Strategy Environment, v.15, 87-102. Doi: 10.1002/bse.450

González-Benito J.(2008) The effect of manufacturing pro-activity on environmental management: an exploratory analysis. International Journal of Production Research, v. 46, 7017-7038. Doi: $10.1080 / 00207540701474021$

González-Benito, J., González-Benito, O. (2010) A study of determinant factors of stakeholder environmental pressure perceived by industrial companies. Business Strategy Environment, v. $19,164-181$.

Hart, S.L.(1995) A natural resourced-based view of the firm. Academy of Management Review, 20 (4), 986-1014. Doi: 10.5465/AMR.1995.9512280033

Hoffman, A.J.(1999) Institutional evolution and change: Environmentalism and the U.S. chemical industry. Academy of Management Journal. 42(4), 351(21 pgs).

Hunt, C. B., Auster, E.L.(1990) Proactive environmental management: avoiding the toxic trap. Sloan Management Review 31 (2), 7-18.

Revista Ibero-Americana de Estratégia - RIAE, São Paulo, v. 11, n. 2, p. 197-224, mai./ago. 2012. 
Levy, D.L., Rothenberg. S.(2002). Heterogeneity and change in environmental strategy: technological and political response to climate change in the global automobile industry. In. Hoffman, A.J., Hoffman, A.J, Vantresca, M.J. Organizations, Policy, and the Natural Environment: Institutional and Strategic Perspective. Stanford University Press,. 173-193, 2002

Lyra, M. G., Gomes, R. C., Jacovine, L. A. G.(2009) O papel dos stakeholders na sustentabilidade da empresa: Contribuições para a construção de um modelo de análise. Revista Administração Contemporânea-RAC., v.13, art. 3, 39-52. Curitiba, Brasil.

Maimon, D.(1994) Eco-estratégia ns empresas brasileiras: realidade ou discurso? Revista da Administração de Empresas 34(4): 119-139.

Masullo, D. G., Lemme, C. F.(set.2005a) Nível de Internacionalização Como Condicionante Da Divulgação De Informações Sobre Responsabilidade Ambiental Nas Grandes Empresas Brasileiras De Capital Aberto. In: EnANPAD, 29. Anais Eletrônicos.... Brasília: ANPAD.

Masullo, D. G., Lemme, C. F.( Nov, 2005b) Relação entre responsabilidade ambiental e setor de atuação. In: ENGEMA, 8,. Anais Eletrônicos... Rio de Janeiro: EAESP/FGV.

Meadows, D. H., Meadows, D. L., Randers, J. ; Behrens III, W. W.(1972) The Limits to Growth, Chicago: Signet.

Mitchell, R. K., Agle B. R., Wood, D. J. (oct. 1997) Toward a theory of stakeholder identification and salience: defining the principle of who and what really counts. The Academy of Management Review, 22(4), 853-886. Doi: 10.5465/AMR.1997.9711022105

Nascimento, L. F., Lemos, A. D. D. C., Mello, M. C. A.(2008) Gestão socioambiental estratégica. Porto Alegre: Bookman.

Orsato, R. J. (2006) Competitive environmental strategies: when does it pay to be green? California Management Review, 48(2), 127-143.

Piovesan, A., Temporini, E. R.(1995) Exploratory research: a methodological procedure applied to the study of human factors in the field of public health. Rev. Saúde Pública. [online], 29(4), 318 325. Doi: 10.1590/S0034-89101995000400010

Porter, M. P., Linde, C. V. D.(Set-oct 1995) Green and Competitive. Harvard Business Review, $.120-134$.

Rugman, A. M.,Verbeke, A.(1998) Corporate strategies and environmental regulations: an organizing framework. Strategic management Journal, v.19, 363-375. Doi: 10.1002/(SICI)10970266(199804)19:4<363::AID-SMJ974>3.0.CO;2-H

Revista Ibero-Americana de Estratégia - RIAE, São Paulo, v. 11, n. 2, p. 197-224, mai./ago. 2012. 
Uma Revisão dos Fatores Determinantes para Proatividade Ambiental: O Caso da Indústria Calçadista

Silva Filho, J. C. L., Abreu, M. C. S., Fernandes, R. M. C., et al. (set/dez. 2008) Análise da gestão ambiental nas companhias estaduais de saneamento básico. Revista Alcance - Eletrônica, 15(3), $322-342$.

Souza, R. S.( Dez. 2002) Evolução dos condicionantes da gestão ambiental nas empresas. READ (Ed. Especial 30), 7(6), 85-112.

Tachizawa, T.(2005) Gestão ambiental e responsabilidade social corporativa. São Paulo, Atlas. (3 . Ed. Revista e Ampliada).

Viola, E. J.(1991) A problemática ambiental no Brasil (1971-1991): da proteção ambiental ao desenvolvimento sustentável. Revista Polis. 3, p. 4-14.

Viola, E. J., Boeira S. L.(1990) Emergência do ambientalismo complexo-multisetorial no Brasil (Particularmente na Microrregião de Florianópolis). Seminário Nacional sobre Universidades e Meio Ambiente, 4. Anais..., Florianópolis.

Viola, E. J., Leis, H. R.(2001) O ambientalismo multisetorial no brasil para além da rio-92: o desafio de uma estratégia globalista viável. In Viola, E. J. et al. Meio Ambiente, desenvolvimento e cidadania: desafios para as ciências sociais. Sao Paulo; Florianópolis: Cortez; Ed. da UFSC.

Yin, R. K.(2010) Estudo de caso: planejamento e métodos. (4 Ed.). Porto Alegre: Bookman.

Recebido:22/05/2012

Aprovado: 25/07/2012

Revista Ibero-Americana de Estratégia - RIAE, São Paulo, v. 11, n. 2, p. 197-224, mai./ago. 2012. 